\title{
La función argumentativa de la referencia explícita al público en la comedia temprana de Aristófanes
}

\author{
María Jimena Schere \\ Universidad de Buenos Aires - Consejo Nacional de Investigaciones \\ Científicas y Técnicas (UBA - CONICET) \\ jimenaschere@hotmail.com
The argumentative function of the explicit reference to the public in the early comedy of Aristophanes

\begin{abstract}
Este trabajo analiza la función argumentativa que desempeña la referencia explícita al público en las comedias aristofánicas del período de Cleón que se centran en polémicas de carácter político. A nuestro entender, la mención expresa del público resulta decisiva para determinar cuáles son los personajes favorecidos en la obra, que operan como portavoces del enunciador-autor. Hay tres tipos de personajes que suelen acceder al privilegio de entrar en contacto directo con sus espectadores: los héroes cómicos, el coro y los esclavos favorables al héroe, que protagonizan la escena de apertura de algunas comedias. En todos los casos, se trata de personajes positivos, que funcionan como portavoces de la postura defendida en la obra o que colaboran con el plan del héroe. Por el contrario, los personajes antagónicos al héroe no gozan de esta prerrogativa. Esta clara diferencia deja de manifiesto el uso intencional del recurso y su valor argumentativo en la comedia temprana.
\end{abstract}

Palabras clave: Referencia al público; argumentación; héroe cómico; portavoz; antagonista.
This work analyzes the argumentative function of the explicit reference to the public in the Aristophanic comedies, focusing on the political plays of the period of Cleon. In our opinion, the express mention of the public is crucial to understand which are the positive characters in the play. There are three types of characters that usually have the privilege of mentioning the spectators: the comic heroes, the choir and the slaves favourable to the hero, who has the leading role in the opening scene of some comedies. In all the cases, it is a positive character, who acts as a spokesman for the enunciator-author or collaborates with the plan of the hero. On the contrary, the antagonistic characters do not enjoy this prerogative. This clear difference demonstrates that the resource has an intentional use and an argumentative function in the early comedy.

Key words: Reference to the public; argumentation; comic hero; spokesman; antagonist. 


\section{INTRODUCCIÓN}

La comedia temprana de Aristófanes pone en escena el enfrentamiento entre un héroe cómico y su adversario. El héroe suele representar el discurso favorecido en la pieza y su oponente constituye el eje del ataque. A través de la construcción de estos personajes antagónicos, la comedia defiende y cuestiona diversas posturas políticas e intenta influir sobre su público. El debate sobre los posibles efectos persuasivos de la comedia atraviesa el siglo XX y sigue siendo una discusión vigente hasta la actualidad. Por lo general, la crítica se ha centrado en detectar los testimonios externos que demostrarían —o rebatirían- la influencia ejercida por la comedia sobre la opinión pública: entre los argumentos en favor de los efectos persuasivos de la comedia se cuentan, por ejemplo, la existencia de decretos para limitar la libertad de los comediógrafos ${ }^{1}$; en contra de esta posición, se ha destacado especialmente la adhesión popular que habrían conservado ciertos personajes históricos como Cleón, pese a los reiterados ataques de los comediógrafos ${ }^{2}$. Desde nuestra perspectiva, los testimonios externos sirven para comprobar los efectos argumentativos concretos que efectivamente pueden haber tenido o no las obras; pero el hecho de que la argumentación no haya convencido al público, al menos de manera inmediata, no prueba que esa dimensión argumentativa no exista; esto vale tanto para el discurso argumentativo ficcional como para el no ficcional. Nuestro análisis deja de lado el problema de los índices externos y se focaliza, en cambio, en el rastreo de las pruebas internas, a fin de demostrar cómo la comedia se vale de estrategias persuasivas para ejercer su influencia sobre el público.

Por otra parte, la crítica ritualista subraya el contexto de licencia excepcional que significaban los festivales teatrales; este enfoque postula que el poder corrosivo que el humor tiene en la asamblea o en las cortes desparece en el marco de los festivales teatrales ${ }^{3}$. A nuestro modo de ver, no es posible limitar la interpretación de la comedia a variantes puramente contextuales. Nos interesa, en cambio, analizar los elementos intrínsecos al texto teatral, es decir, los índices internos que revelan la intención argumentativa del come-

\footnotetext{
${ }^{1}$ Cf. Sommerstein 1996b.

${ }^{2}$ Cf. Halliwell 1984a, 1984b, 1991a, 1991b, 1993, 2008; Heath 1987.

${ }^{3}$ Cf. Halliwell 1984; Bowie 1993; Riu 1999. A nuestro parecer, es necesario estudiar la comedia no tanto como un espacio ritual, sino como un espacio ciudadano, vinculado con otras instituciones ciudadanas. Al respecto, Henderson 1990, p. 273, ha subrayado el fuerte vínculo existente entre el teatro, la asamblea y los tribunales.
} 
diógrafo. En este sentido, este trabajo se propone demostrar que la mención explícita del público por parte de ciertos personajes desempeña una función argumentativa en la comedia de Aristófanes.

Nos centramos en el estudio de las piezas tempranas, desde la comedia Acarnienses (425 a. C.) hasta Paz (421 a. C.), etapa dominada por la influencia de Cleón, líder de la democracia radical. Estas obras desarrollan polémicas de carácter político e intentan influir de manera clara sobre la opinión pública contemporánea: Acarnienses (425 a. C.) y Paz (421 a. C.) se focalizan en la polémica contra la política belicista; Caballeros (424 a. C.) ataca a los demagogos de la democracia radical, en particular, a Cleón; Avispas (422 a. C.) cuestiona las relaciones entre el poder político y el judicial ${ }^{4}$. En el período de Cleón, precisamente, el comediógrafo asienta su postura sobre problemáticas centrales de la realidad ateniense y despliega sus blancos predilectos: los líderes de la democracia radical y los partidarios de la guerra del Peloponeso. Esta serie de comedias se caracteriza, además, por presentar dos personajes centrales enfrentados, que constituyen el núcleo de la pieza y el eje del debate político planteado en ella: en Acarnienses (425 a. C.) el héroe Diceópolis, defensor de la paz con Esparta, disputa contra su antagonista Lámaco, representante del belicismo; Caballeros (424 a. C.) plantea la controversia entre los dos protagonistas, Morcillero y Paflagonio, que rivalizan por liderar al pueblo; también Avispas (422 a. C.) pone en escena el conflicto entre el sensato Bdelicleón y el malvado juez Filocleón; por último, la comedia Paz (421 a. C.) presenta los embates del campesino Trigeo, impulsor de la paz, contra su enemigo Pólemos, una personificación de la guerra. En suma, las comedias del período adoptan un esquema binario —un portavoz del discurso favorecido y su antagonista-, estructura común que permite analizarlas de manera conjunta.

Desde nuestra perspectiva, la apelación y la mención expresa del público que asistía a los festivales resultan decisivas para determinar cuáles son los personajes favorecidos en la pieza, que operan como portavoces del enunciador-autor ${ }^{5}$. Este recurso, por lo tanto, colabora con la estrategia persuasi-

${ }^{4}$ Dentro de la producción aristofánica del período de Cleón, dejamos de lado la comedia Nubes en tanto esta obra involucra sobre todo una polémica particular, de carácter retóricofilosófico, contra la sofística y la nueva educación.

${ }^{5}$ Los términos «enunciador» y «enunciatario» suelen hacer referencia a una construcción discursiva. El enunciador tiene una identidad interna al discurso, que se diferencia del emisor externo o sujeto empírico, que posee una identidad social (cf. Charaudeau y Maingueneau 
va de las obras, en la medida en que orienta a los espectadores sobre las preferencias del comediógrafo. En primer lugar, nos detendremos en el análisis de Acarnienses, la primera comedia conservada del autor, para definir los rasgos salientes que caracterizan el empleo del recurso; en segundo orden, abordaremos el resto de las obras del período para poder apreciar el modo común en que todas ellas se valen de la misma estrategia con fines persuasivos; en último término, haremos una breve referencia a la producción posterior.

\section{LA MENCIÓN DEL PÚBLICO EN ACARNIENSES}

La comedia Acarnienses, compuesta en el marco de la guerra del Peloponeso, pugna en favor de la tregua entre Atenas y Esparta6: el campesino Diceópolis asume el discurso favorable a la paz y sus oponentes en escena, como son el coro de acarnienses o el general Lámaco, abogan por la continuidad de las hostilidades. El héroe Diceópolis pronuncia dos largos discursos sin interrupción en los que asienta su postura: el monólogo de apertura de la obra y un extenso parlamento en el que se dirige al público y al coro de carboneros de Acarnes, quienes pretenden lapidarlo por haber concertado una tregua privada con Esparta. En este largo discurso (vv. 496-556), que según se ha argumentado cumple la función que en otras obras desempeña el agón epirremático $^{7}$, Diceópolis adopta un papel complejo que conjuga la figura de

2005 [2002], pp. 541-542). En la comedia aristofánica, el emisor es el autor de la obra, mientras que el enunciador-autor es la identidad del autor, de carácter discursivo, que se construye en el propio discurso teatral.

${ }^{6}$ Gran parte de los estudios aristofánicos modernos, desde los editores de la obra hasta sus críticos, considera que Acarnienses aboga seriamente por el cese de las hostilidades contra Esparta. Dentro de los editores podemos mencionar a Starkie 2009 [1909], Sommerstein 1992 [1980] y Henderson 2006 [1998]. Entre los críticos que han avalado tempranamente esta lectura se cuentan, por ejemplo, Murray 1933, p. 27, Murphy 1938, p. 79, y De Ste. Croix 1996 [1972], p. 59, cuya influencia ha sido notoria en los estudios aristofánicos posteriores. En los años ochenta, reafirman expresamente esta visión Newiger 1996 [1980], Edmunds 1980, pp. 29-30, y MacDowell 1983. Desde la década de los noventa hasta la actualidad, se suman autores como Van Steen 1994, Nichols 1998, pp. 27-76, Moorton 1999, Zumbrunnen 2004 y Tritle 2010, p. 91.

7 Gelzer 1960, pp. 166-168, observa que Acarnienses carece de un agón epirremático. Edmunds 1980, p. 8, subraya que el agón (no formal) de Acarnienses (vv. 490-625) se centra 
un simple campesino, la del misio Télefo ${ }^{8}$ y la del propio autor ${ }^{9}$, y realiza un alegato de autodefensa ante el coro hostil de acarnienses. Diceópolis defiende primero la importancia de la comedia y su capacidad de decir cosas justas; ataca al líder político Cleón en respuesta a las acusaciones presuntamente realizadas por el demagogo en contra del comediógrafo ${ }^{10}$; habla en favor de la paz y manifiesta su rencor contra los lacedemonios por haber destruido sus tierras, pero los excusa de la responsabilidad exclusiva de la guerra; por último, relaciona el origen de las hostilidades con el robo de prostitutas de Aspasia, la amante de Pericles, como una manera de ridiculizar la guerra y ligarla a los intereses personales del líder.

El héroe Diceópolis, disfrazado con los harapos de Télefo, abre su extenso discurso persuasivo dirigiéndose directamente a los espectadores ( $\not \alpha \nu \rho \varepsilon \varsigma$ oi $\theta \varepsilon \omega ́ \mu \varepsilon v o 1$, v. 496):

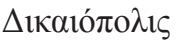

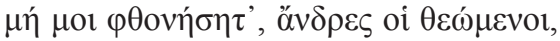

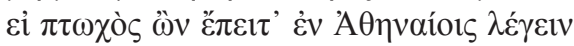

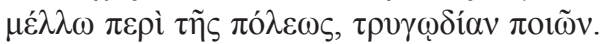

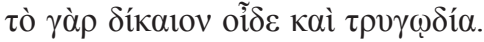
$\dot{\varepsilon} \gamma \omega \grave{\delta} \delta \grave{\varepsilon} \lambda \dot{\varepsilon} \xi \omega \delta \varepsilon ı \grave{\alpha} \mu \grave{\varepsilon} v, \delta i ́ \kappa \alpha \iota \alpha \delta \dot{\varepsilon}^{11}$.

en el discurso de Diceópolis, a diferencia del modelo típico que incluye un enfrentamiento entre dos personajes.

${ }^{8}$ Diceópolis hace su discurso disfrazado con los harapos de Télefo, rey de Misia y personaje central de una tragedia de Eurípides. Sobre la historia de Télefo y la versión euripidea, véanse Handley y Rea 1957, Rau 1967, pp. 19-42, Foley 1988, MacDowell 1995, pp. 53-58.

${ }^{9}$ Fisher 1993 destaca la pluralidad de identidades que asume el héroe: campesino, héroe trágico, héroe cómico, portavoz del poeta, etc. Al respecto, véanse también Foley 1988, p. 40, Van Steen 1994, p. 219, Dobrov 1995 y, más recientemente, Kentch 2008, p. 51.

${ }^{10}$ Este es uno de los pasajes en los que el personaje se identifica directamente con el autor. Cleón habría emprendido acciones legales por la comedia Babilonios contra el comediógrafo o contra el productor Calístrato. Sobre las presuntas acciones legales de Cleón contra Aristófanes, véanse Halliwell 1991b, Atkinson 1992, Henderson 1998, Sommerstein 2004a, 2004b. Halliwell 1991b, por ejemplo, considera que las representaciones teatrales estaban al margen de las sanciones legales por el contexto de licencia excepcional que significaban los festivales teatrales. Henderson 1998, por el contrario, argumenta que no hay evidencias de que el ataque contra individuos fuera más tolerado en los festivales que en la asamblea.

${ }^{11}$ Utilizamos la edición de Wilson 2007 para todas las citas textuales y las referencias a la comedia de Aristófanes. Las traducciones son propias. 
No os indignéis conmigo, señores espectadores, si aun siendo un mendigo, voy a hablar ante los atenienses acerca de los asuntos públicos representando una comedia. Pues también la comedia conoce lo justo. Y yo voy a decir cosas terribles, pero justas.

(vv. 496-501)

En toda la comedia Acarnienses, Diceópolis es el único personaje que tiene el privilegio de utilizar el vocativo explícito para referirse al público. Sin duda, su empleo exclusivo en boca del héroe permite propiciar una especial empatía y una comunicación directa entre este personaje y su audiencia. Dobrov (1995) ha observado que la invocación directa al público logra incorporarlo en la ficción ${ }^{12}$; podemos agregar, además, que esta invocación genera una simpatía entre el personaje que la utiliza y los espectadores y, por lo tanto, tiene una clara finalidad argumentativa. Por otra parte, el recurso aparece en una parte clave de la obra en la que Diceópolis asienta de manera manifiesta e inequívoca su posición a favor de la tregua. No solo en esta oportunidad el héroe nombra a su audiencia; antes de su discurso argumentativo, Diceópolis emplea también la misma estrategia:

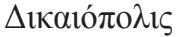

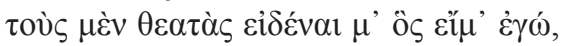

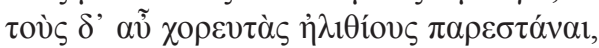

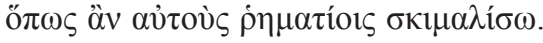
Los espectadores deben saber quién soy, pero los coreutas deben estar ahí parados como imbéciles, para que yo me mofe de ellos con frasecitas

(vv. 442-444)

En este caso, el héroe cómico entra en complicidad con sus espectadores, si bien no los invoca de manera directa. Diceópolis intenta ponerlos de su parte al marcar la diferencia entre el conocimiento superior de la audiencia, que está al tanto de su verdadera identidad oculta bajo el disfraz de mendigo, y la ingenuidad del coro, a quien pretende burlar con frasecitas.

Más adelante, en la parábasis, el coro de carboneros de Acarnes también tiene el privilegio de referirse a la audiencia ( $\tau$ ò $\theta \varepsilon ́ \alpha \tau \rho o v, ~ v . ~ 629)$, pero ya no bajo la forma de invocación, sino en tercera persona:

12 Dobrov 1995, p. 58. 
Xopós

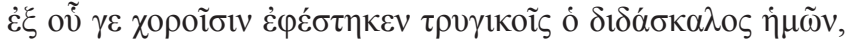

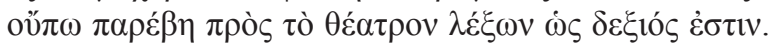

Coro: Desde que nuestro productor ${ }^{13}$ está al frente de coros de comedia todavía no avanzó hacia el público para decir que es hábil.

(vv. 628-629)

Por lo general, el coro suele entrar en contacto directo con el público en las parábasis y quebrar la ilusión dramática ${ }^{14}$. A esta altura de la representación, el coro ya ha abrazado la postura del protagonista, convencido por sus argumentos; en este sentido, podemos afirmar que la mención del público en la obra sigue siendo una prerrogativa de los personajes positivos, ya sea el héroe o sus aliados.

Es preciso aclarar que Diceópolis constituye un personaje positivo en la medida en que actúa como portavoz del discurso favorecido en la obra, es decir, la defensa de la paz, visión que domina también en una serie de comedias posteriores como Paz y Lisístrata. Eso no significa que Diceópolis sea un personaje idealizado; por cierto, la comedia aristofánica no presenta ningún personaje totalmente intachable ni carente de defectos. Se ha hablado mucho, por ejemplo, del egoísmo de Diceópolis, que rehúsa compartir la paz con otros personajes $^{15}$. Sin embargo, como bien ha observado MacDowell ${ }^{16}$, la conducta de Diceópolis, aun cuestionable, tiene el atenuante de que el personaje solo pacta su tregua privada y adopta una postura egoísta luego de que sus planes de lograr la paz para toda la pólis han sido rechazados por sus conciudadanos.

${ }^{13}$ Se refiere al poeta (Olson 2002, p. 236).

14 Sifakis 1971 niega que exista la ilusión dramática en la obra de Aristófanes. Sin embargo, coincidimos con Thiercy 1986, p. 139, en que resulta abusivo cuestionar la existencia de la ilusión teatral en la comedia aristofánica. Para una discusión actualizada sobre el tema, véase Cottone 2005, pp. 33-41.

15 Whitman 1964, pp. 78-79, destaca el egoísmo del héroe. En una misma línea, Dover 1972, pp. 87-88, compara el egoísmo de Diceópolis, que se niega a compartir la paz con otros personajes, con la acción benéfica de Trigeo. Thiercy 1986, p. 197, por su parte, considera que la simpatía que genera el héroe en la primera parte de la obra contrasta con la antipatía que produce su actitud egoísta en la segunda. También han advertido el egoísmo de Diceópolis Newiger 1996 [1980], p. 147, Bowie 1993, p. 39, Foley 1988.

${ }_{16}$ MacDowell 1983. Por su parte, Parker 1991, p. 206, argumenta con acierto que el pretendido egoísmo de Diceópolis encuentra un atenuante en la ceguera de sus conciudadanos, hecho que diferencia la situación de Trigeo y del héroe de Acarnienses. 
La mención expresa del público por parte de Diceópolis y del coro los alinea en una misma franja y los ubica en una posición destacada al ser una ventaja exclusiva de estas figuras, de la que no goza ningún otro personaje de la obra. Sin embargo, cabe subrayar que el uso que realiza Diceópolis en su extenso discurso provoca aún mayor empatía que el empleo del coro porque el vocativo permite una comunicación todavía más directa con los espectadores. Ade-

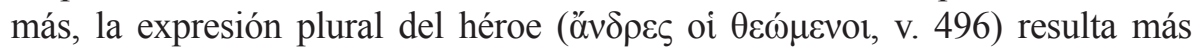
personalizada y puede generar mayor proximidad que la referencia colectiva al

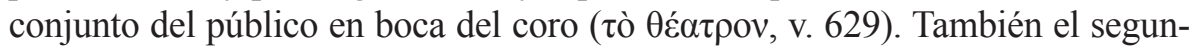
do empleo del héroe ( $\theta \varepsilon \alpha \tau \alpha ́ s$, v. 442) se vale de una expresión en plural, en lugar de utilizar el colectivo neutro $\theta \varepsilon ́ \alpha \tau \rho o v$. Por último, podemos destacar, de acuerdo con nuestro registro, que Diceópolis es el primer personaje en la obra que goza de este privilegio (vv. 442 y 496). En definitiva, la primera comedia conservada de Aristófanes utiliza el recurso con el fin de captar la adhesión de la audiencia y beneficiar a los personajes positivos de la obra, en particular, al campesino Diceópolis, el más firme partidario de la tregua.

\section{LA MENCIÓN DEL PÚBLICO EN CABALLEROS}

La comedia Caballeros lleva a escena el conflicto suscitado entre los esclavos de Demos, personaje que encarna la figura colectiva del pueblo ateniense. Los esclavos representan a los líderes políticos contemporáneos que rivalizan por alcanzar la mayor influencia sobre el pueblo votante. En la apertura de la pieza, el esclavo Demóstenes, en su diálogo con el servidor Nicias ${ }^{17}$, hace referencia explícita a los espectadores en plural: '¿Quieres que explique el

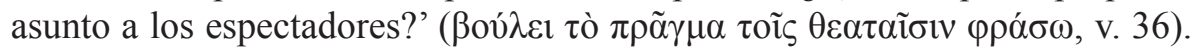
Demóstenes emplea por primera vez, antes que ningún otro personaje de la obra, la palabra $\theta \varepsilon \alpha \tau \alpha i ́$ (v. 36); con este anuncio, comienza a relatar las desgracias que ha desencadenado la llegada del nuevo esclavo Paflagonio en la casa de Demos y realiza un retrato totalmente negativo del personaje (vv. 4072). Paflagonio representa con claridad al demagogo contemporáneo Cleón,

${ }^{17}$ Los dos esclavos que enfrentan a Paflagonio representan a Nicias y Demóstenes, según los manuscritos medievales. Nicias pertenecía al ala política moderada y rivalizaba con la línea radical de Cleón. El general Demóstenes, por su parte, fue el impulsor de la campaña de Pilo. Sommerstein 1981, pp. 144-145, acepta la identidad de los dos servidores. Cf. Dover 1959 y Henderson 2003, 2006, p. 222. 
que lideraba la asamblea ciudadana en la Atenas contemporánea. En este caso, la mención explícita en boca de Demóstenes favorece desde el inicio la complicidad del público con su postura contraria a Cleón ${ }^{18}$.

Demóstenes vuelve a referirse de manera directa a su auditorio en el verso 228. En esta ocasión el héroe cómico de la pieza, Morcillero, se resiste a aceptar la propuesta de Demóstenes y Nicias que lo incitan a batirse con Paflagonio y arrebatarle el liderazgo sobre el pueblo. Morcillero, un vendedor de embutidos, pregunta con escepticismo quiénes lo apoyarán en su lucha contra Paflagonio-Cleón. Demóstenes, entonces, incluye entre los futuros colaboradores del héroe a los caballeros, a las personas decentes y a los espectadores inteligentes:
$\Delta \eta \mu о \sigma \theta \dot{v} \eta \varsigma_{S}$

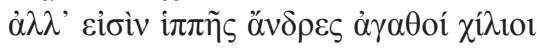

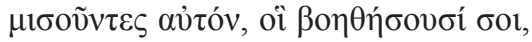

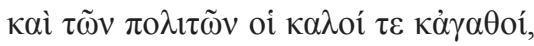

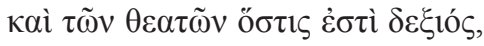

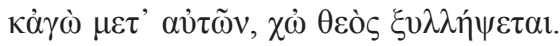

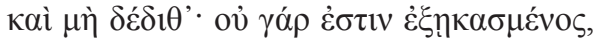

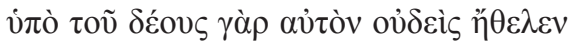

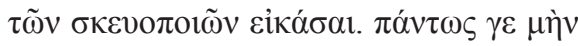

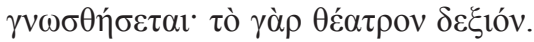

Hay mil caballeros, hombres nobles, que, como lo odian, te ayudarán y de entre los ciudadanos los buenos y nobles, y de entre los espectadores todo el que sea inteligente, y yo estaré con estos, y el dios ayudará.

No temas, porque no lleva una máscara con su propia cara; pues por temor ningún fabricante quiso retratarlo. De todos modos, se lo reconocerá, pues el público es inteligente.

(vv. 225-233)

En este pasaje Demóstenes, además de nombrar de manera explícita al público ( $\tau \tilde{\omega} v \theta \varepsilon \alpha \tau \tilde{\omega} v$, v. 228), lo elogia en forma sutil (v. 233) como un recurso para captar su benevolencia y ponerlo de su parte: primero afirma que cuenta con la ayuda de los espectadores inteligentes ( $\delta \varepsilon \xi$ เó $\varsigma$, v. 228) y, finalmente, in-

18 Thiercy 2001, p. 207, observa que mediante esta mención se logra integrar al público en la acción dramática. 
cluye en esta categoría al conjunto de la audiencia (v. 233), suficientemente perspicaz como para reconocer a Cleón detrás de la máscara ${ }^{19}$. Asimismo, Demóstenes presenta aquí toda la plana completa de personajes favorecidos en esta obra, incluidos los espectadores, y los encolumna detrás de su figura y la de Morcillero. Una vez más la referencia expresa tiene la función argumentativa de alinear al público con los personajes enfrentados a Paflagonio-Cleón.

También la parábasis de Caballeros emplea el mismo recurso. En este caso, aparece en boca del coro de caballeros, enemigos acérrimos del líder:

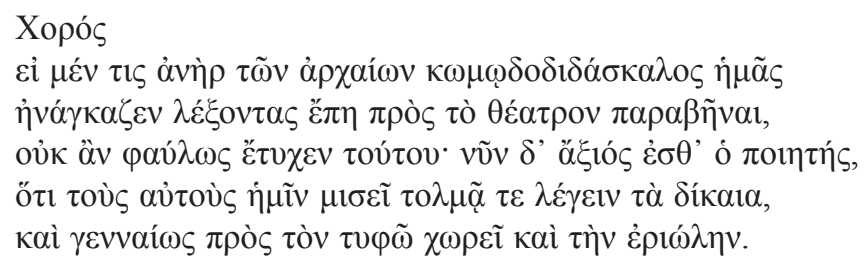

Coro: $\mathrm{Si}$ alguno de los antiguos productores de comedias nos hubiera forzado a avanzar hacia el público para decir unas palabras, no lo hubiera conseguido fácilmente; pero ahora el poeta es digno de esto, porque odia a los mismos que nosotros y se atreve a decir cosas justas y marcha noblemente contra el tifón y el huracán.

(vv. 507-511)

El coro destaca la valentía y la capacidad de decir cosas justas del poeta, tópicos que también utiliza en Acarnienses (p. ej. v. 645) ${ }^{20}$. La nueva mención del público ( $\tau$ ò $\theta \varepsilon \dot{\varepsilon} \alpha \tau \rho o v$, v. 508) intenta provocar su adhesión a estos postulados sobre la función del comediógrafo. Según se observa también en Acarnienses, en las parábasis la referencia al público suele tener el propósito de reforzar la simpatía del auditorio hacia la figura del poeta ${ }^{21} \mathrm{y}$, consecuentemente, hacia la postura propuesta en la obra.

19 Este pasaje ha dado lugar a una discusión sobre la fabricación de máscaras en la antigüedad y sobre el aspecto físico del Cleón histórico. Cf. Dover 1975 [1967], Welsh 1979, Olson 1999.

${ }^{20}$ El tópico de lo justo era empleado frecuentemente por los oradores contemporáneos (cf. Murphy 1938, p. 90). Por lo tanto, el poeta desdibuja de esta manera la frontera entre comediógrafo y líder político, entre discurso teatral y discurso deliberativo, entre espectadores y asamblea.

${ }^{21} \mathrm{La}$ apelación del poeta (a través del coro) a los espectadores y el elogio del poeta son motivos convencionales de la parábasis. Al respecto, cf. Sifakis 1971, pp. 37-44, y Hubbard 1991, pp. 17-23. 
Finalmente, también el personaje de Demos se vale del término, precisamente en el momento previo a su metamorfosis positiva (v. 1210), cuando debe elegir entre su viejo y corrupto líder Paflagonio-Cleón y su nuevo líder, Morcillero. A pesar de la imagen negativa que presenta Morcillero hasta este punto de la obra, en el desenlace el héroe cómico viene a propiciar una política distinta a la de Cleón ${ }^{22}$. Demos apela a los espectadores ( $\left.\theta \varepsilon \alpha \tau \alpha i ́\right)$ para involucrarlos en la decisión del líder correcto, captar su atención y ganar su complicidad $^{23}$ :
$\Delta \tilde{\eta} \mu \mathrm{s}$

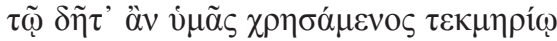

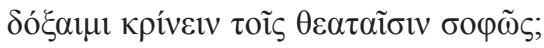
Demos: ¿Qué signo probatorio podría utilizar
para que los espectadores consideren que juzgo hábilmente?

(vv. 1209-1210)

Morcillero propone que Demos revise la canasta de ambos (vv. 12111213). Demos accede y comprueba que la de Morcillero está vacía, pero que Paflagonio se ha guardado algunas cosas pertenecientes a su amo (vv. 12141220), revelación que decide la victoria de Morcillero (vv. 1227-1228). La mención de los espectadores se presenta en una parte clave de la obra e invita al público a cambiar de liderazgo político de la mano de Demos, su alter ego en escena.

El último personaje que nombra al público directamente es el héroe cómico de la pieza, Morcillero ( $\theta \dot{\varepsilon} \alpha \tau \rho o v$, v. 1318). Después de la segunda parábasis, Morcillero sale a escena con una imagen totalmente purificada, que será

${ }^{22}$ En Caballeros el nuevo liderazgo de Morcillero significa la adopción por parte de Demos de una serie de medidas políticas opuestas a la orientación de Cleón. El nuevo programa político de Demos (vv. 1365-1380) apunta, en primer lugar, a asegurar el legítimo salario de los remeros (vv. 1366-1367); prohíbe que los hoplitas, una vez enrolados, puedan por su influencia cambiar de inscripción (p. ej. ser incluidos en otra clase etaria o en caballería en vez de infantería; vv. 1369-1371). Por último, Demos propone evitar la influencia de los jóvenes políticos adiestrados en el arte de la retórica (vv. 1373-1380). En este sentido, a pesar de la imagen negativa de Morcillero en toda la pieza, el desenlace presenta una imagen renovada del personaje.

${ }^{23}$ Slater 2002, p. 80, considera que hasta este punto Demos constituye un objeto de burla y no se pretende que el espectador se identifique con el personaje, a pesar de su nombre; en cambio, a partir de esta apelación al público se intenta producir efectivamente la identificación. 
la dominante hasta el final. En su primer parlamento, menciona a los espectadores, una marca de enunciación favorable que indica su transformación y lo acerca de lleno al auditorio:

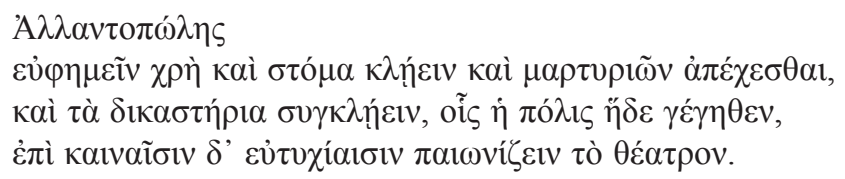

A $\lambda \lambda \alpha v \tau о \pi \dot{\lambda} \lambda \uparrow \varsigma$

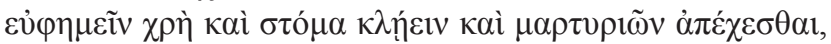

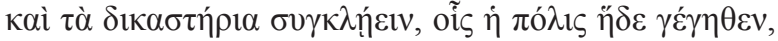

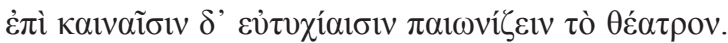

Es necesario guardar silencio religioso, cerrar la boca, abstenerse de [testimonios y clausurar los tribunales con los que se regocija esta ciudad y que el público entone un peán por la nueva buena fortuna.

(vv. 1316-1318)

Morcillero viene a comunicar la buena noticia de que ha cocido a Demos y de que lo ha transformado en un hombre bello: Demos ha vuelto a ser el dêmos de la vieja Atenas, el vencedor de Maratón, el de las guerras contra los persas cuando Atenas era liderada por hombres como Aristides y Milcíades (vv. 1321-1328) ${ }^{24}$. Morcillero comenta, además, que gracias a su acción Demos ya no huele a votos en los tribunales, sino a libaciones de paz (vv. 1331-1332). En definitiva, el último registro del término «espectadores» tiene la función argumentativa clave de señalar cuál es la postura vencedora en la pieza y de intentar persuadir al público de la necesidad de cambiar el rumbo político impuesto por Paflagonio-Cleón. En conclusión, hemos verificado que todos los personajes que hacen uso del recurso en Caballeros (Demóstenes, el coro, Demos y Morcillero una vez reformados) se caracterizan por sostener una visión contraria a Cleón, el blanco central de la pieza.

\section{LA MENCIÓn Del PÚBLICO EN AVISPAS Y PAZ}

La comedia Avispas repite el esquema de apertura de Caballeros: los dos esclavos del héroe Bdelicleón inauguran la pieza y presentan el punto de vista de su amo, coincidente con el del enunciador-autor. Los esclavos de Bdelicleón comentan que su amo intenta mantener encerrado en su casa a su padre,

\footnotetext{
${ }^{24}$ Sommerstein 1981, p. 215.
} 
Filocleón, para evitar que este satisfaga su compulsión insana de juzgar a sus conciudadanos y de condenar a todos los acusados sin excepción. El joven Bdelicleón, a nuestro entender, constituye el héroe cómico de la pieza porque es el portavoz del enunciador-autor, así como Diceópolis o Trigeo en otras comedias $^{25}$. En efecto, Bdelicleón asume la crítica contra los abusos de los jueces atenienses y cuestiona la sumisión del poder judicial al poder político. Por su parte, su antagonista Filocleón encarna el principal contradiscurso atacado en la obra, esto es, la práctica deshonesta de la actividad judicial en la Atenas contemporánea. Los servidores de Bdelicleón resultan favorables al héroe en tanto colaboran con él en su propósito de mantener encerrado al anciano, quien intenta burlar la vigilancia y escapar hacia los tribunales ${ }^{26}$. Como ocurre en la comedia Caballeros, el esclavo Jantias, al igual que Demóstenes, hace mención de los espectadores al presentar el argumento de la obra:

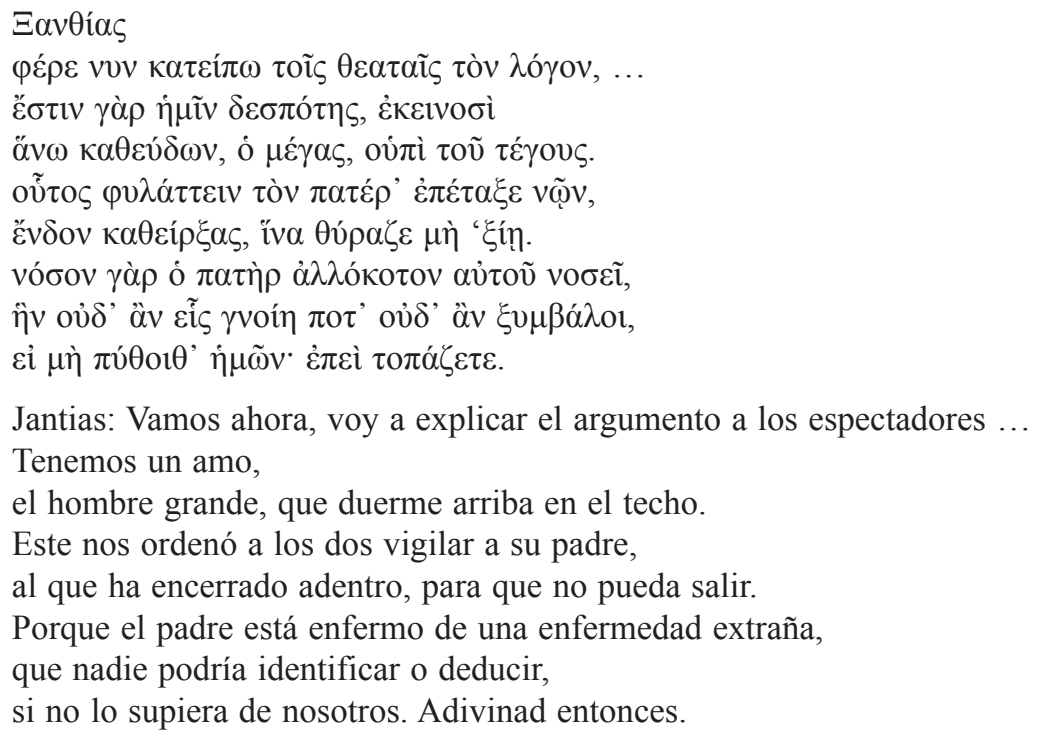

(vv. 54-73)

${ }^{25}$ La identificación del héroe en la comedia Avispas ha dado lugar a controversias. Para una visión distinta a nuestro enfoque, véanse Whitman 1964, Dover 1972, Paduano 1974, McLeish 1980, Thiercy 1986.

${ }^{26}$ Sommerstein 1996a, p. 158, señala que el hijo Bdelicleón, debido a la vejez del padre, es la cabeza del hogar; por lo tanto, consideramos que los dos esclavos responden al héroe, en este caso Bdelicleón, como ocurre en Caballeros y Paz. 
El término $\theta \varepsilon \alpha \tau \alpha i ́$ en boca de Jantias sirve, como en las obras anteriores, para generar empatía entre el público y la postura presentada, en este caso, la visión negativa del juez Filocleón y de su conducta en los tribunales ${ }^{27}$. Paduano (1974) ha señalado que la exposición del esclavo rompe la ilusión dramática, apenas establecida ${ }^{28}$; es preciso agregar una vez más que la ruptura tiene asimismo una función argumentativa.

También en la parábasis de Avispas el coro de jueces menciona al público en varias oportunidades (vv. 1013, 1016, 1071), una vez que ha adoptado la postura del héroe Bdelicleón. Si bien el coro comienza por apoyar la visión del antagonista, luego se vuelca claramente del lado del héroe; solo entonces se vale del término, como ocurre en el caso del coro de Acarnienses. Finalmente, las avispas vuelven a emplearlo una vez más en el cierre de la obra (v. 1526). A esta altura del análisis, podemos afirmar con seguridad que el recurso constituye una marca enunciativa ${ }^{29}$ de aplicación sistemática en las obras tempranas, que orienta sobre las preferencias del enunciador-autor.

En la comedia $\mathrm{Paz}$, por último, se reitera la misma estrategia. El héroe Trigeo, quien lidera la liberación de la diosa $\mathrm{Paz}^{30}$, tiene el privilegio del uso de la palabra «espectadores»: arroja granos a su público y, de este modo, lo hace participar de la celebración conjunta por el cese de la guerra

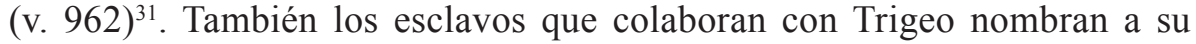
público en los versos 43 y 964; la mención inicial del verso 43 cumple una función semejante a la observada en las escenas de apertura de Caballeros y Avispas:

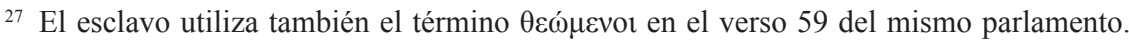

${ }^{28}$ Paduano 1974, p. 9.

${ }^{29}$ Las marcas de enunciación son las marcas de subjetividad que el sujeto de la enunciación le imprime a su discurso. Sobre la inscripción del locutor en el propio enunciado, véase Kerbrat-Orecchioni 1993 [1980].

${ }^{30}$ La mayor parte de la crítica sostiene que esta obra celebra la tregua inminente: por ejemplo, Dover 1972, p. 137, De Ste Croix 1996 [1972], p. 61, Newiger 1996 [1980], p. 152, Cassio 1985, p. 36, Hubbard 1991, p. 140, Bowie 1993, p. 134, Carey 1993, p. 246, Slater 2002, p. 131; Kanavou 2011, p. 190. Komornicka 1964, p. 80, por su parte, sugiere incluso que la comedia puede haber influido positivamente en las negociaciones de paz.

${ }^{31}$ El esclavo del héroe Trigeo también nombra a los espectadores en los versos siguientes (v. 964). Por su parte, Trigeo vuelve a emplear el término «espectadores» en el verso 1115. Asimismo, el personaje hace otras varias alusiones al público en la obra, pero que no incluyen los significativos términos explícitos recién mencionados (p. ej. vv. 150, 244, 276, 821). 


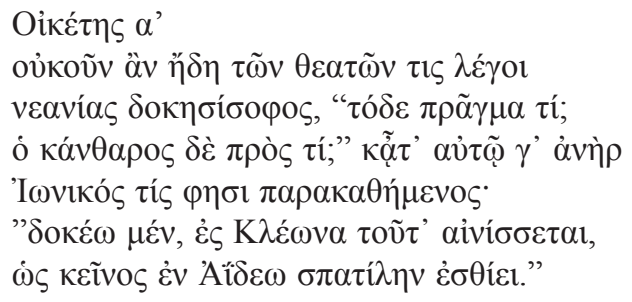

Servidor a: Y bien, ahora alguno de entre los espectadores podría decir, un joven que se crea sabio: «¿Qué es esto?

¿Para qué el escarabajo?»Y entonces algún hombre

jonio, sentando a su lado le dice:

«Creo que esto alude a Cleón

porque aquel come en el Hades excremento».

(vv. 43-48)

En este parlamento el esclavo hace referencia al escarabajo de su amo, que ambos servidores alimentan para que Trigeo pueda volar hasta los dioses y abogar por la paz entre los griegos. La mención del público por parte del esclavo predispone favorablemente al auditorio respecto de la postura que será defendida por el héroe cómico de la pieza. Los dos esclavos se burlan de Cleón, que por ese entonces ya había fallecido, pero que había sido en vida uno de los principales detractores de la tregua entre Atenas y Esparta. Del mismo modo, según observamos, en Avispas los esclavos del héroe nombran a los espectadores en la apertura de la obra como un modo de acercarlos a la posición de su amo Bdelicleón, contrario a las prácticas judiciales deshonestas y a la sumisión de los jueces al poder político. Asimismo, en Caballeros el esclavo Demóstenes menciona al público a fin de destacar desde el comienzo su visión hostil a Cleón.

Por último, en la comedia Paz también se valen del recurso el coro (v. 732), afín al héroe desde el inicio, y el Hermes benéfico (vv. 543, 658), luego de colaborar con Trigeo para liberar a Paz. En suma, en la última comedia del período de Cleón también los personajes positivos (i. e. el héroe, sus esclavos, sus colaboradores y el coro) tienen el monopolio de referirse al auditorio y favorecer, de esta manera, su punto de vista.

V. La mención del pÚblico en las obras posteriores al aÑo 421 A. C.

La crítica aristofánica ha observado la diferencia existente entre las obras tempranas de la época de Cleón y el resto de la producción del comediógra- 
fo. Por ejemplo, Gil Fernández 1993 considera que las comedias del primer período, de 427 a 421, son de carácter satírico por su actitud crítica contra su objeto, mientras que en las obras posteriores el poeta pierde su «ímpetu combativo ${ }^{32}$ y se vuelve irónico. MacDowell 1995, por su parte, advierte también la regularidad presente en las piezas tempranas: de los políticos contemporáneos, Cleón constituye su blanco principal ${ }^{33}$. Asimismo, Slater 2002 destaca la importancia del líder en la producción del período: los recursos metateatrales, que ponen de manifiesto la condición de la comedia como construcción teatral, entre ellos la apelación al público ${ }^{34}$, sirven como medio para criticar la manipulación dramática de los políticos atenienses y enseñan a los ciudadanos a mirar más allá del disfraz y la actuación; en particular, las obras tempranas proponen una «estrategia común» ${ }^{35}$ para relacionarse con el demagogo Cleón.

Además de su virulencia satírica y de la presencia unificadora de Cleón, las obras de esta etapa permiten detectar, como señalamos, una estructura común: la existencia de dos protagonistas antagónicos que representan un discurso positivo y un discurso negativo ${ }^{36}$. El esquema binario resulta propicio

32 Gil Fernández 1993, p. 30.

33 MacDowell 1995, p. 353.

${ }^{34}$ Slater 2002, p. 18.

35 Slater 2002, p. 236.

36 También Nubes termina por plantear un enfrentamiento entre el héroe Estrepsíades y su antagonista Sócrates: al final de la pieza, Estrepsíades reniega de las enseñanzas de la sofística e incendia el «pensadero»; en este sentido, Estrepsíades asumiría finalmente el discurso positivo, contrario a la nueva educación. Sin embargo, Nubes se aleja en muchos puntos de la serie analizada y, por lo tanto, requiere un comentario aparte. En primer lugar, involucra una polémica de carácter retórico-filosófico contra la sofística y la nueva educación, eje vinculado con la polémica política, pero de manera indirecta; en cambio, en las otras obras la polémica política es central. En segundo lugar, la comedia Nubes solo incluye la mención expresa del público en boca del coro (vv. 518, 521, 535, 575) y de los argumentos justo (v. 890) e injusto (v. 1096). El recurso no resulta tan significativo en esta pieza porque no es utilizado por ningún personaje central ( $\mathrm{p}$. ej. el héroe). Por otra parte, el coro tiene una posición sumamente cambiante y compleja en la obra: si bien representa en principio a la escuela de los sofistas, en la parábasis habla en nombre del poeta para criticar a los espectadores; asimismo, en el final de la obra parece cambiar de condición y sostiene que castiga a los injustos. En las otras obras tempranas, en cambio, el coro tiene una posición definida, si bien puede cambiar de signo a lo largo de la pieza: el coro de Acarnienses primero ataca al héroe, pero luego es convencido por sus argumentos; lo mismo ocurre con el coro de Avispas. Los coros de Caballeros y de $\mathrm{Paz}$ son colaboradores del héroe desde el inicio. Un último aspecto destacable 
para poner en escena polémicas políticas y comunicar una postura definida ${ }^{37}$. Esta estructura deja huellas, sin duda, en la producción posterior del comediógrafo, pero se vuelve más flexible y pierde su relevancia. Aves, por ejemplo, carece de un antagonista unificado; tampoco en Tesmoforiantes o Asambleístas es posible identificar con claridad la figura de un antagonista. En Ranas Eurípides podría ocupar este lugar, pero no encontramos en ella la estructura clásica del héroe enfrentado directamente con un rival central. Pluto opone las figuras de Riqueza y Pobreza, pero no presenta la disputa característica entre el héroe y su adversario. Tan solo en Lisistrata el personaje del $\pi \rho \beta_{\beta} \beta 0 v \lambda \circ \varsigma$ se acerca a la figura del antagonista; quizás el uso del esquema temprano se deba en este caso al hecho de que Lisistrata retoma la temática de la tregua presente en las obras del período de Cleón ${ }^{38}$. En las obras tempranas, la existencia de un héroe positivo y de un rival bien reconocible, que encarna el discurso negativo, permite que la pieza transmita un mensaje político mucho más claro que las comedias posteriores. La mención explícita del público es un recurso más que colabora en ellas con la claridad del mensaje. Por cierto, hemos intentado demostrar que las primeras comedias conservadas, en las cuales el autor asienta su postura y sus blancos predilectos, revelan una intención clara de influir sobre el público; en las piezas posteriores, en cambio, la dimensión polémica y argumentativa, si bien está presente, suele perder intensidad.

Si hacemos un recorrido sucinto por las obras posteriores a $\mathrm{Paz}$, podemos destacar algunas particularidades del uso del recurso. En Aves la mención aparece solo en boca del coro (vv. 446, 753, 786) ${ }^{39}$ : en el verso 446, el cori-

es que contamos solo con una versión revisada de Nubes, datada alrededor del año 417, fecha posterior al período de Cleón. En suma, la comedia Nubes, por sus particularidades, se aleja en muchos aspectos de las obras tempranas conservadas y requiere un análisis diferenciado.

${ }^{37}$ Otro elemento argumentativo central, común a las obras tempranas, es el orden de aparición de los personajes. En las obras del período, el primer personaje protagónico que sale a escena es el héroe cómico de la pieza y el portavoz del discurso positivo. Al respecto, véase Schere 2013.

${ }^{38}$ McLeish 1980, p. 56, destaca la presencia clara de un héroe y su principal adversario en Acarnienses, Caballeros, Nubes, Avispas, Paz, Lisístrata y Pluto. Considera que el antagonista de Lisístrata es el oficial ateniense y que en Pluto Pobreza es el rival de los héroes Carión y Crémilo. En cambio, reconoce que no hay antagonista en Aves, Tesmoforiantes, Ranas y Asambleistas. Coincidimos con la interpretación de McLeish, con la salvedad de que la comedia Pluto no se ajusta exactamente al esquema de las primeras obras.

${ }^{39}$ Evélpides no hace mención del público, pero utiliza el vocativo $\tilde{\omega} v \delta \rho \varepsilon \varsigma$ (v. 30) al comienzo de la pieza para referir el motivo de la partida de los dos personajes. Este uso se 
feo solicita a los jueces y a los espectadores que premien la obra, estrategia habitual en la comedia; por su parte, los versos 753 y 783 pertenecen a la parábasis. Aves mantiene la lógica de reservar la mención para los aliados del héroe Pistetero, en este caso el coro de aves. Por cierto, Pistetero encarna una visión crítica de Atenas, representada por su alejamiento de la ciudad; en este sentido, es el principal portavoz del enunciador-autor. Sin embargo, podemos observar que la referencia al público pierde eficacia en tanto no es utilizada en ningún momento por el héroe. En las comedias tempranas, en cambio, el empleo del recurso permite ubicar en una misma franja al héroe y a sus aliados (Acarnienses, Caballeros, Paz) o a los esclavos del héroe y al coro (Avispas). Por otra parte, en Aves la mención se emplea tan solo en sus usos más formulares y convencionales: primero, se utiliza para captar la benevolencia de los jueces del certamen y, luego, en la parábasis, como es habitual en la comedia $^{40}$. En suma, si bien la referencia al auditorio sigue siendo una prerrogativa de los aliados del héroe, el recurso pierde su fuerza argumentativa porque no aparece en boca del protagonista, no alinea a los personajes favorecidos y se conserva tan solo para el coro en sus usos más convencionales.

En Lisistrata y Tesmoforiantes ya no se hace referencia expresa a los espectadores del teatro ${ }^{41}$. Esta interrupción debilita, sin duda, la fuerza argumentativa del recurso en las obras más tardías, en las que vuelve a ser utilizado. En Ranas y en Asambleístas, con todo, se mantiene la lógica característica de las obras tempranas. En Ranas solo el coro y los aliados del héroe Dioniso lo utilizan. El primer registro aparece en boca del esclavo de Dioniso, Jantias (v. 2); sin embargo, el esclavo se refiere más bien a los espectadores en general, que se ríen siempre de los mismos chistes estereotipados, y no a los espectadores presentes en la representación. Luego, hace expresa mención Heracles (v. 132), quien colabora con el plan del héroe. Asimismo, el coro elogia la sabiduría del público y su capacidad de comprensión (vv. 1110 y 1118). Por último, al final de la pieza, el héroe Dionisio asegura que el público está de acuerdo con su decisión de llevarse

\footnotetext{
acerca, al menos, a la mención por parte del esclavo que relata el eje del conflicto en Caballeros (v. 36) y Avispas (v. 54).

40 La apelación directa al público es una forma convencional de la parábasis (Sifakis 1971, p. 38; Hubbard 1991, p. 18).

${ }^{41}$ En Tesmoforiantes una mujer que participa en la asamblea utiliza el término $\theta \varepsilon \alpha \tau \alpha i ́$ (v. 391), pero no para hacer mención de los espectadores presentes en la representación, sino para referirse a los espectadores del trágico Eurípides.
} 
de regreso a Esquilo (v. 1475) ${ }^{42}$. En definitiva, el héroe y sus colaboradores se presentan alineados por esta vía. Subrayamos especialmente la última aparición del término en boca de Dioniso, quien intenta generar la complicidad del público respecto a su decisión de rescatar a Esquilo; en este caso, el recurso tiene una finalidad claramente argumentativa.

En Asambleístas domina también el mecanismo de la obra temprana: la heroína Praxágora (v. 583), el coro femenino (v. 582) y una criada de la heroína (v. 1141) nombran al público expresamente. Praxágora es la principal representante de la postura del enunciador-autor en tanto asume una visión crítica de la realidad ateniense. La excepción al uso es la mención que realiza un personaje ocasional, una mujer joven: la muchacha se enfrenta con una anciana que reclama su derecho a tener relaciones sexuales con un hombre joven (v. 888). En este caso, la joven denuncia los excesos del nuevo sistema utópico propuesto por las mujeres. Más allá de este registro particular, la heroína y sus colaboradoras (el coro y su criada) aparecen unificadas bajo el empleo del término.

Finalmente, en la comedia Pluto, el propio personaje de Pluto se refiere al chiste recurrente en la comedia de arrojar higos a los espectadores (v. 798). Esta mención no resulta muy significativa para la interpretación de la obra, pero mantiene la lógica de poner el término en boca de los personajes positivos; Pluto lo utiliza una vez que ha recuperado la vista y beneficia a los honrados.

En síntesis, en la obra posterior al período de Cleón el recurso tiene un uso muy limitado, pierde presencia y, por lo tanto, fuerza argumentativa. Sin embargo, los personajes que lo utilizan suelen ser aquellos que sostienen una postura crítica en relación con la realidad ateniense o que colaboran con el plan del héroe: el coro de Aves, el héroe Dionisio y sus colaboradores, Praxágora y sus aliadas, el personaje de Pluto recuperado de su ceguera.

\section{Conclusiones}

De acuerdo con nuestro rastreo en las comedias del período de Cleón, hay tres tipos de personajes que suelen tener el privilegio de mencionar al público y entrar en contacto directo con él: 1) los héroes cómicos; 2) el coro, especialmente en las parábasis cuando ya se ha volcado del lado del protagonista;

42 Eurípides menciona expresamente a los espectadores de Esquilo, pero no al público presente (vv. 909, 919, 926). 
3) los esclavos favorables al héroe, que protagonizan la escena de apertura de algunas comedias. En todos los casos, se trata de personajes positivos, que funcionan como portavoces del enunciador-autor y que colaboran con el plan del héroe. Por el contrario, los personajes antagónicos a la postura del héroe no gozan de esta prerrogativa. Esta clara diferencia deja de manifiesto el uso intencional del recurso y su valor argumentativo. En las comedias posteriores, el recurso pierde presencia y relevancia, pero aun así suele ser un privilegio de los personajes que asumen una postura crítica contra la realidad ateniense, como son los héroes Dioniso, Praxágora y sus colaboradores.

La comedia, por su carácter ficcional y humorístico, posee una ambigüedad constitutiva en cuanto al mensaje político de las obras. En este sentido, la referencia explícita al auditorio es una de las estrategias discursivas que el comediógrafo emplea, a nuestro entender, para guiar la interpretación de su público. El espectador ateniense, familiarizado con el recurso, podía orientarse en cuanto a las preferencias del autor. Por el carácter repetitivo y convencional del recurso, cuando un personaje nombraba a los espectadores, el público teatral podía anticipar que se trataba de un personaje positivo e identificar cuál era la postura defendida en la pieza. La mención expresa del público permitía, entonces, aportar cierta claridad, al menos parcial, a la compresión del mensaje presente en las obras.

La mención del público no solo permite identificar al portavoz del discurso positivo, sino que además produce una ruptura de la ilusión dramática y la consecuente cercanía cómplice con el personaje al modo de una captatio benevolentiae. Por cierto, el recurso suele emplearse en la obra temprana al comienzo de los parlamentos que asientan claramente cuál es el punto de vista favorecido en la pieza y cuál su blanco central de ataque, como el discurso de Diceópolis en Acarnienses o la introducción al argumento de la obra por parte de un esclavo del héroe. En definitiva, a pesar de que algunos estudiosos de la obra aristofánica han negado la dimensión argumentativa de la comedia, la detección de esta estrategia dominante en las piezas tempranas constituye una prueba clara de las intenciones argumentativas del comediógrafo.

\section{BiBLIOGRAFÍA}

Atkinson, J. E. 1992: «Curbing the Comedians: Cleon versus Aristophanes and Syracosius' Decree», The Classical Quarterly (New Series) 42, 1, pp. 56-64<http:// journals.cambridge.org/> (02/05/2012), doi 10.1017/S0009838800042580. 
Bowie, A. M. 1993: Aristophanes. Myth, Ritual and Comedy, Cambridge.

Carey, Ch. 1993: «The purpose of Aristophanes' Acharnians», Rheinisches Museum 136, pp. 245-263.

Cassio, a. C. 1985: Commedia e partecipazione. La pace di Aristofane, Napoli.

Charaudeau, P. y Maingueneau, D. 2005 [2002]: Diccionario de análisis del discurso, Buenos Aires-Madrid (trad. española Agoff, I.).

Cottone, R. S. 2005: Aristofane e la poetica dell' ingiuria. Per una introduzione alla loidoría comica, Roma.

De Ste Croix, G. E. M. 1996 [1972]: «The Political Outlook of Aristophanes», en Segal, E. (ed.), Oxford Readings in Aristophanes, Oxford-New York, pp. 42-64.

Dobrov, G. W. 1995: «The Poet's Voice in the Evolution of Dramatic Dialogism», en Dobrov, G. W. (ed.), Beyond Aristophanes. Transition and Diversity in Greek Comedy, Atlanta-Georgia, pp. 47-97.

Dover, K. J. 1959: «Aristophanes, Knights 11-20», The Classical Review 9, 3, pp. 196-199.

Dover, K. J. 1975 [1967]: «Portrait-Masks in Aristophanes», en Newiger, H.-J. (ed.), Aristophanes und die alte Komödie, Darmstadt, pp. 155-169.

Dover, K. J. 1972: Aristophanic Comedy, Berkeley-Los Ángeles.

Edmunds, L. 1980: «Aristophanes' Acharnians», en Henderson, J. (ed.), Aristophanes. Essays in interpretation, Yale Classical Studies 26, pp. 1-41.

Fisher, N. R. E. 1993: «Multiple Personalities and Dionysiac Festivals: Dicaeopolis in Aristophanes' 'Acharnians'», Greece \& Rome 40, 1, pp. 31-47 <http://journals. cambridge.org/> (02/05/2012), doi 10.1017/S0017383500022579.

Foley, H. 1988: «Tragedy and Politics in Aristophanes' Acharnians», The Journal of Hellenic Studies 108, pp. 33-47.

Gelzer, Th. (1960): Der epirrhematische Agon bei Aristophanes. Untersuchungen zur Struktur der attischen alten Komödie (Zetemata 23), München.

Gil Fernández, L. 1993: «La comicidad en Aristófanes», Cuadernos de Filología Clásica. Estudios griegos e indoeuropeos 3, pp. 23-39.

Halliwell, S. 1984a: «Aristophanic Satire», The Yearbook of English Studies 14, pp. 6-20.

Halliwell, S. 1984b: "Ancient Interpretations of onomasti komodein in Aristophanes», The Classical Quarterly (New Series) 34, 1, pp. 83-88<http://journals. cambridge.org/> (02/05/2012), doi 10.1017/S0009838800029311.

Halliwell, S. 1991a: «The Uses of Laughter in Greek Culture», The Classical Quarterly (New Series) 41, pp. 279-296<http://journals.cambridge.org/> (02/05/2012), doi 10.1017/S0009838800004468.

Halliwell, S. 1991b: «Comic Satire and Freedom of Speech in Classical Athens», The Journal of Hellenic Studies 111, pp. 48-70.

Halliwell, S. 1993: "Comedy and Publicity in the Society of the Polis», en Sommerstein, A. H., Halliwell, S., Henderson, J. y Zimmermann, B. (eds.), Tragedy, 
Comedy and the Polis. Papers from the Greek Drama Conference (Nottingham, 18-20 July 1990), Bari, pp. 321-340.

Halliwell, S. 2008: Greek Laugther. A Study of Cultural Psychology from Homer to Early Christianity, Cambridge.

Handley, E. W. y Rea, J. 1957: The Telephus of Euripides, London.

Heath, M. 2007 [1987]: Political Comedy in Aristophanes, Göttingen.

Henderson, J. 1990: «The Demos and the Comic Competition», en Winkler, J. J. y Zeitlin, F. I. (eds.) Nothing to do with Dionysos? Athenian Drama in its Social Context, Princeton - New Jersey, pp. 271-313.

Henderson, J. 1998: «Attic Old Comedy, Frank Speech, and Democracy», en Boedeker, D. y Raaflaub, K. A. (eds.), Democracy, Empire, and the Arts in FifthCentury Athens, Cambridge-Massachusetts, pp. 255-273.

Henderson, J. (ed.) 2006 [1998]: Aristophanes. Acharnians. Knights, vol. 1, Cambridge-Massachussets.

Henderson, J. 2003: "When an identity was expected: the slaves in Aristophanes' Knights», en G. W. Bakewell y Sickinger, J. P (eds.), Gestures. Essays in Ancient History, Literature, and Philosophy Presented to Alan L. Boegehold. On the occasion of his retirement and his seventy-fifth birthday, Oxford, pp. 63-73.

Hubbard, T. K. 1991: The Mask of Comedy. Aristophanes and the Intertextual Parabasis, Ithaca-London.

Kanavou, N. 2011: Aristophanes' Comedy of Names. A Study of Speaking Names in Aristophanes, Berlin-New York.

Komornicka, A. M. 1964: Métaphores, personnifications et comparaisons dans l'oeuvre d'Aristophane, Wroclaw-Warszawa-Kraków.

Kentch, G. 2008: Euripidaristophanizing. Tragedy and Comedy in Four Plays of Aristophanes, Tennessee.

Kerbrat-Orecchioni, C. 1993 [1980]: La enunciación. De la subjetividad en el lenguaje, Buenos Aires (trad. española Anfora, G. y Gregores, E.).

MacDowell, D. M. 1983: "The Nature of Aristophanes' 'Akharnians'», Greece \& Rome 30, 2, pp. 143-162 http://journals.cambridge.org/ (02/05/2012),10.1017/ S0017383500027091.

MacDowell, D. M. 1995: Aristophanes and Athens. An Introduction to the Plays, Oxford.

McLeish, K. 1980: The Theatre of Aristophanes, London.

Moorton, R. F. 1999: «Dionysus or Polemos? The Double Message of Aristophanes' Acharnians», en Titchener, F. B. y Moorton, R. F. (eds.), The Eye Expanded. Life and the Arts in Greco-Roman Antiquity, Berkeley, pp. 24-51.

Murphy, Ch. T. 1938: «Aristophanes and the Art of Rhetoric», Harvard Studies in Classical Philology 49, pp. 69-133.

Murray, G. 1933: Aristophanes. A Study, Oxford. 
Newiger, H.-J. 1996 [1980] «War and Peace in the Comedy of Aristophanes», en Segal, E. (ed.), Oxford Readings in Aristophanes, Oxford-New York, pp. 143-161.

Nichols, P. 1998: Aristophanes' Novel Forms. The Political Role of Drama, AtlantaLondon-Sydney.

Olson, D. S. (ed.) 1998: Aristophanes. Peace, Oxford.

Olson, D. S. 1999: «Kleon's Eyebrows (Cratin. fr. 228 K-A) and Late 5th-Century Comic Portrait-Masks», The Classical Quarterly (New Series) 49, 1, pp. 320-321 $<$ http://journals.cambridge.org/> (02/05/2012), 10.1093/cq/49.1.320.

Olson, D. S. (ed.) 2002: Aristophanes. Acharnians, Oxford.

Paduano, G. 1974: Il giudice giudicato. Le funzioni del comico nelle Vespe di Aristofane, Bologna.

Parker, L. P. E. 1991: «Eupolis or Dicaeopolis?», The Journal of Hellenic Studies 111, pp. 203-208.

Rau, P. 1967: Paratragodia. Untersuchungen einer komischen Form des Aristophanes, München.

Riu, X. 1999: Dionysism and Comedy, Lanham - Boulder - New York - Oxford.

Schere, M. J. 2013: «El orden de aparición de los personajes en los prólogos aristofánicos y su función argumentativa», Revista de Estudios Clásicos 40 (en prensa).

Sifakis, G. M. 1971: Parabasis and Animal Choruses. A Contribution to the History of Attic Comedy, London.

Slater, N. W. 2002: Spectator Politics. Metatheatre and Performance in Aristophanes, Philadelphia.

Sommerstein, A. H. (ed.) 1992 [1080]: The comedies of Aristophanes. Acharnians, vol. 1, Warminster.

Sommerstein, A. H. (ed.) 1981: The comedies of Aristophanes. Knights, vol. 2, Warminster.

Sommerstein, A. H. (ed.) 1996a [1983]: Aristophanes. Wasps, vol. 4, Warminster.

Sommerstein, A. H. 1996b: «How to Avoid Being a komodoumenos», The Classical Quarterly 46, 2, pp. 327-356.

Sommerstein, A. H. 2004a: "Comedy and the unspeakeable», en Cairns, D. L y Knox, R. A. (eds.), Law, Rhetoric And Comedy in Classical Athens, Swansea, pp. 205-222.

Sommerstein, A. H. 2004b: «Harassing the Satirist: The Alleged Attempts to Prosecute Aristophanes», en Sluiter, I. y Rosen, R. M. (eds.), Free Speech in Classical Antiquity (Mnemosyne Suppl. 254), Leiden-Boston, pp. 145-174.

Starkie, W. J. M (ed.) 2009 [1909]: The Acharnians of Aristophanes, Charleston.

Thiercy, P. 1986: Aristophane: fiction et dramaturgie, Paris.

Thiercy, P. 2001: «Choreutes et spectateurs dans les comédies d'Aristophane», en González de Tobia, A. M. (ed.), Los griegos: otros y nosotros, La Plata, pp. 201217. 
Tritle, L. A. 2010: A New History of the Peloponnesian War, Oxford.

Van Steen, G. A. H. 1994: «Aspects of 'Public Performance' in Aristophanes' Acharnians», L’antiquité Classique 63, pp. 211-224.

Welsh, D. 1979: «Knights 230-3 and Cleon's Eyebrows», The Classical Quarterly (New Series) 29, 1, pp. 214-215 < http://journals.cambridge.org/> (02/05/2012), doi $10.1017 /$ S0009838800035333.

Whitman, C. 1964: Aristophanes and the Comic Hero, Cambridge-Massachusetts.

Wilson, N. G. (ed.) 2007: Aristophanis Fabulae (2 vol.), Oxford.

Zumbrunnen, J. 2004: «Elite Domination and the Clever Citizen: Aristophanes' Archarnians and Knights», Political Theory 32, 5, pp. 656-677.

Fecha de recepción de la primera versión del artículo: 17/05/2012

Fecha de aceptación: 12/04/2013

Fecha de recepción de la versión definitiva: 30/05/2013 